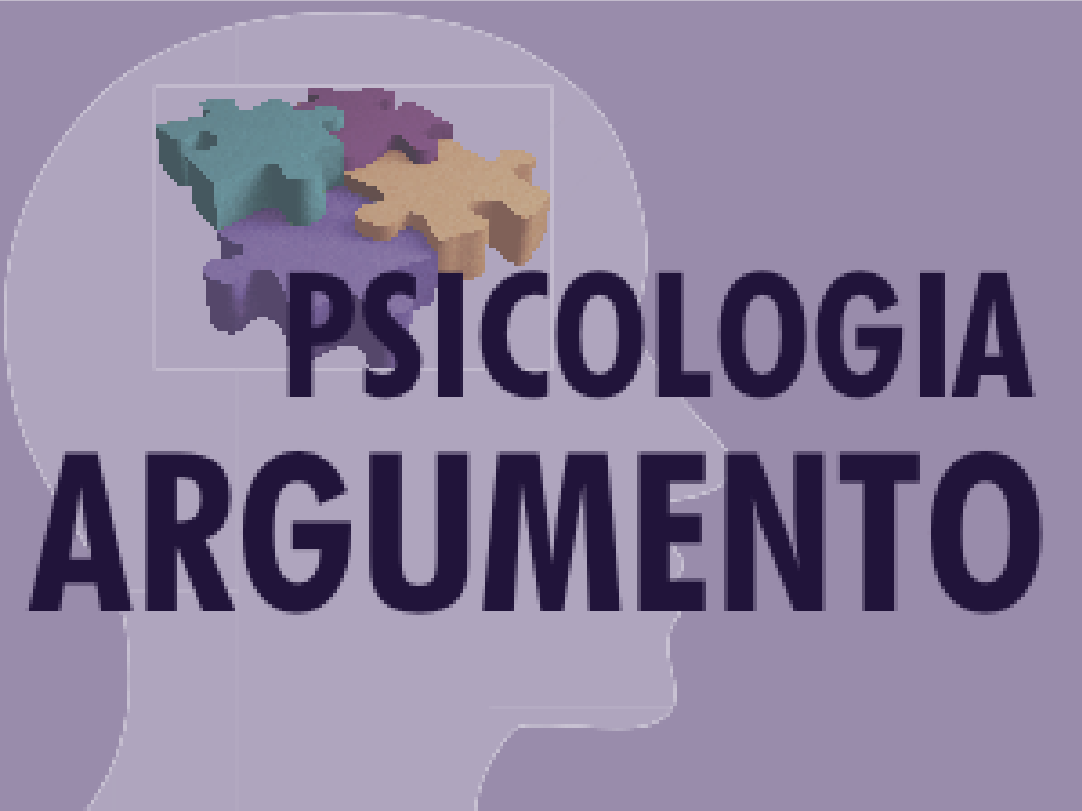

ISSN 0103.7013 Licencindo sch uma licença Creative Commons

\title{
Armário de vidro: (re)conhecendo as políticas públicas e os direitos sexuais da população LGBT
}

Glass Closet: $(\mathrm{Re})$ knowing the public policies and sexual rights of the LGBT population

\section{Luís Fernando da Veiga ${ }^{[a]}$, Moises Romanini ${ }^{[b]}$,}

[a] Psicólogo, Graduado em Psicologia pela Universidade de Santa Cruz do Sul, Santa Cruz do Sul, RS, Brasil, luisf_veiga@yahoo.com.br

[b] Psicólogo, Professor de Psicologia pela Universidade de Santa Cruz do Sul, Santa Cruz do Sul, RS, Brasil, moisesromanini@unisc.br

\section{Resumo}

Os atravessamentos sobre gênero e sexualidades da população LGBT perpassam os caminhos das pluralidades e das singularidades, e são imbuídas de interconexões entre o espaço público e privado nas políticas públicas e sociais. Esta pesquisa analisou reportagens veiculadas pela mídia escrita, em um jornal do interior do Estado do Rio Grande do Sul, sobre fatos ou opiniões relacionadas ao público/tema LGBT problematizando os discursos veiculados e tomando como norteadores as noções de discurso do filósofo francês Michel Foucault, de performatividade de gênero e de cisheteronormatividade refletindo sobre as políticas públicas destinadas a garantir os direitos dessas populações. O garimpo jornalístico encontrou 44 reportagens envolvendo os discursos de gênero e sexualidade em seus enunciados abarcando o período entre setembro de 2014 e junho de 2016. Ao elencar os discursos analisados nesta pesquisa utilizou-se a analogia entre alguns diferentes tipos de vidros existentes em decorrência dos jogos linguísticos disponíveis para abordar a complexidade da população LGBT.

Palavras-chave: LGBT; Performatividade; Cisheteronormatividade; Mídia Escrita; Análise do Discurso. 


\begin{abstract}
The crossing between gender and sexuality in the LGBT's population goes beyond the pluralities and singularities' paths, and are immerse in an interconection between public and private space on the public and social's politics. This research's objective was to analyze reports linked to the written media, on an local newspaper from the interior of Rio Grande do Sul, about facts and opinions related to the LGBT's population/theme and to problematize the speeches related to the written media by taking the notions of speech - from the french philosopher Michael Foucault-, gender performativity and cis-heteronormativity as a north to think about public politics designated to ensure the rights of these populations. The search on the newspapers has found 44 reports involving gender and sexuality's speeches on its headline, in the period of time that goes from September 2014 to June 2016. On listing the analyzed speeches in this research, it was used the analogy between some different types of glasses as a result of the linguistic games available to approach the complexity of the LGBT's population.
\end{abstract}

Keywords: LGBT; performativity; cisheteronormativity; written media; speech analysis.

\title{
Introdução
}

As sexualidades e as questões de gênero, em um dilatado sentido dos termos, envolvem as subjetividades e os modos de vida, abarcando, assim, um combo de atravessamentos ilimitados. Desde longa data, as sociedades vivem de modo a contemplar os binarismos e, consequentemente, instituem padrões de normalidade, patologizando o que não se enquadra num pressuposto fixado (Foucault, 2007; Butler, 2003). Esse paradigma engessa as diversidades, marginalizando e violentando modos de vida que destoem à normatividade $\mathrm{e}$ negando o direito de viver livremente.

O presente artigo objetiva compartilhar uma forma de realizar pesquisa sobre gênero e sexualidade a partir da noção de discurso do filósofo francês Michel Foucault, pois privilegia a interdisciplinaridade e a atribuição de identidades sociais aos universos encontrados abarcando as interconexões entre poder e verdade e também utilizando a performatividade e a cisheteronormatividade que são ferramentas conceituais dos Estudos de Gênero e Sexualidade das Ciências Humanas.

A discussão que abarca a temática envolvendo a performatividade de gênero (BUTLER, 2003) é emaranhada pelos cunhos subjetivos, culturais e interpessoais e perpassam as relações de poder e formas de controle das sociedades imbricadas por ideologias, ações políticas e sociais. Neste sentido, a cisheteronormatividade pode ser considerada um dos efeitos da performatividade de gênero em sociedades que estabelecem razões e verdades absolutas, vigiando as regras comportamentais de gênero e da sexualidade.

Utilizaremos a nomenclatura cisheteronormatividade que abarca a intersecção entre as normativas referentes à orientação sexual e as relacionadas à identidade de gênero. Segundo Pino (2007), a heteronormatividade é o enquadramento de todas as relações em um binarismo de gênero que organiza 
suas práticas, atos e desejos a partir do modelo do casal heterossexual reprodutivo. Bagagli $(2013,2017)$ propõe pensarmos em cisgeneridade compulsória como dispositivo de regulação sexual, afetiva e social na vida de pessoas trans, travestis e transexuais e de sujeitos cisgêneros que se relacionam com pessoas transgêneras, dessa maneira se torna possível a crítica política da matriz cisgênera, que estabiliza o gênero através da cisnormatividade.

A sigla LGBT representa o movimento e a articulação de lésbicas, gays, bissexuais, travestis, transexuais e transgêneros, nesse sentido, LGB reconhece as identidades sexuais de lésbicas, gays e bissexuais e o $T$ abrange as identidades de gênero das pessoas trans com toda e qualquer orientação sexual. Será adotada a sigla LGBT durante todo o escrito, pois é a mais utilizada pelos movimentos sociais brasileiros e por entidades governamentais, como conselhos e secretarias nos três âmbitos da federação.

A pesquisa está imbricada na análise do discurso midiático escrito, onde se constituem espaços de reprodução em massa e nicho de pesquisa para o garimpo do material disposto no jornal de maior circulação de um município do interior do Rio Grande do Sul. Não existem soluções simples para as questões de identidade e diferença e diante do cenário das questões de gênero e sexualidades da população LGBT nos municípios de pequeno porte, questiona-nos como a mídia escrita (disponibilizada online) tem veiculado reportagens relacionadas a essa temática.

\section{MÉTODO}

Temos como objetivo explanar a pesquisa de cunho qualitativo, exploratório e descritivo que envolveu a análise do discurso midiático escrito a partir do garimpo de material jornalístico, problematizações das questões de gênero e sexualidade e sobre as políticas públicas destinadas a garantir os direitos da população LGBT. As discussões caminham no sentido de compreender as formas pelas quais os poderes se emaranham a discursos a fim de produzir efeitos de verdade.

Os discursos dispõem regras internas e externas que ordenam os sentidos e produzem efeitos de verdades e produção social de sentidos. Para Foucault (2007), o discurso é um bem que tem suas regras de aparecimento e também suas condições de apropriação e de utilização: um bem que se coloca, por conseguinte, desde sua existência (e não simplesmente em suas aplicações práticas), e a questão do poder; um bem que é o objeto de uma luta política.

Pensando na formação do discurso inserido em um contexto específico e buscando problematizar as suas relações e atravessamentos, foi escolhido o jornal de um munícipio no interior do estado do Rio Grande do Sul e as buscas foram feitas no site da empresa.

As amostras foram não probabilísticas intencionais e representaram os universos pesquisados. $O$ instrumento para a produção de dados foi caracterizado pelo garimpo de recortes jornalísticos no período entre setembro de 2014 e junho de 2016 e que envolvesse as questões de gênero e sexualidade da população LGBT. As palavras selecionadas no sistema de busca do site foram LGBT; GLS; 
lésbica(s); gay(s); bissexual(is); travesti(s); transexual(is); trans; preconceito; homofobia; transfobia; sexualidade; gênero; sexo; direitos humanos.

O período inicial para a escolha dos recortes é o ano de 2014, pois foi neste momento que se intensificou a presença da temática analisada neste estudo. Os anos que antecederam não apresentaram grandes referências à população LGBT na mídia pesquisada. Serão apresentadas algumas características objetivas dos textos veiculados para contextualizar as condições de (re)produção dos discursos, buscando elementos que transversalizam as reportagens analisadas na sua relação entre discurso e formas de subjetivação.

\section{RESULTADOS E DISCUSSÕES: ONDE DEIXEI A MINHA CHAVE?}

Ao elencar os discursos analisados nesta pesquisa, utilizou-se a analogia entre alguns diferentes tipos de vidros existentes em decorrência dos jogos linguísticos disponíveis para abordar a complexidade das identidades de gênero e da cisheteronormatividade. Esse jogo de palavras acompanhará a reflexão de Eve Kosofsky Sedgwick (2007), que propôs a Epistemologia do Armário, ou seja, uma reflexão sobre o "armário" como um dispositivo de regulação entre o público e o privado na vida de gays e lésbicas e que abarca também os privilégios de pessoas heterossexuais cisgêneros.

Aproveitamos a analogia do armário para todos os indivíduos pertencentes ao grupo LGBT e não somente para a população de gays e lésbicas cisgêneros como referida na proposta original. Essa combinação gramatical entre armário e vidro resultou no título e discussão deste escrito.

Quanto à busca realizada, foram encontradas 44 reportagens envolvendo os discursos de gênero e de sexualidade em seus enunciados principais. A totalidade dos escritos se encontra em formato online do jornal. As assinaturas confirmam 25 vezes mulheres cisgêneras, 3 homens cisgêneros e 15 não tiverem assinatura física, somente jurídica ou não foram assinalados autores e autoras.

Foram encontradas reportagens na página principal do site que é austera com formato informativo em tons claros, maior parte descritiva. $E$ também em dois cadernos do jornal, o primeiro voltado para o público jovem escolar e acadêmico com um formato colorido, dinâmico e extrovertido. O outro caderno é direcionado predominantemente para o público jovem feminino falando sobre moda, beleza, comportamento e sexualidade e suas cores são vibrantes em tons rosa e vermelho e tendo mais imagens ilustrativas.

A partir da análise das reportagens apresentamos duas grandes categorias. A primeira, "Abrem-se alguns armários". Dentro desta, elencamos quatro subcategorias: "Armário de vidro blindado"; "Armário de vidro temperado estilhaçado"; O "Armário de vidro transparente acústico"; "Armário de vidro fumê" e "Armário de vidro cristal". E, por fim, a categoria intitulada "Direitos sexuais, direitos humanos e políticas públicas: encontrando as chaves perdidas dos armários".

ABREM-SE ALGUNS ARMÁRIOS 
Em 2014 a população brasileira viveu um ano eleitoral delicado. Dez candidatos concorreram à presidência da república e Dilma Rousseff concorreu à reeleição a qual resultou no seu segundo mandato como presidenta do Brasil. Nos debates eleitorais televisionados em canais abertos do país os candidatos tiveram a chance de defender as propostas dos seus programas de governo e mais do que em qualquer outro momento histórico, trouxeram como pauta as políticas públicas ligadas a LGBTs. Posicionamentos considerados pelo grande público como polêmicos, tanto pela esfera religiosa que os acompanhava, como pelos entendimentos distintos do que seria aceitável na sociedade brasileira.

Em setembro de 2014, o jornal investigado circulou a reportagem que buscou os candidatos a deputados estaduais do município a fim de elencarem os seus posicionamentos referentes à união de pessoas do mesmo sexo. Assinada por um homem cisgênero teve a sua divulgação online e impressa.

Dos quatro candidatos entrevistados, dois mostraram-se contrários ao casamento igualitário e dois a favor. Um deles destaca que a maioria dos seus eleitores é contrária a esta liberação e, por representar uma parcela de pessoas, precisa seguir o desejo dos que acompanham o seu trabalho, afirmando que respeita as escolhas de cada um, que é um seguidor da fé cristã, e por isso, defende o casamento tradicional. Para o candidato, a discussão é polêmica e precisa ocorrer no Brasil, afirma que não ter preconceitos é fundamental, mas informa ser contrário à permissão entre pessoas do mesmo sexo.

É, sem dúvida, um traço comum a muitas sociedades que as regras de conduta sexual variem segundo a idade, o sexo, a condição dos indivíduos, e que obrigações e interdições não sejam impostas a todos da mesma maneira. Mas, para se ater ao caso da moral cristã, essa especificação se faz no quadro de um sistema global que define, de acordo com princípios gerais, o valor do ato sexual, e indica sob que condições ele poderá ou não ser legitimo, sendo a pessoa casada ou não, ligada ou não por votos, etc, trata-se aí de uma universalidade modulada (FOUCAULT, 2007).

Outro candidato argumenta Não tenho preconceitos, mas acredito que o país não está preparado para isso. Se tiver que votar esse tipo de projeto, serei contrário. Defendo a família e a moralidade. E segue: Não vejo benefícios neste tipo de liberação, de que forma estes casais iriam criar seus filhos. Não traria melhorias para a população. Eu não fico em cima do muro. Sou contrário e prezo pela moral e bons costumes.

Como ressalta Foucault (2007, p. 135), em suma, para ser dita "moral", uma ação não deve se reduzir a um ato ou a uma série de atos conformes a uma regra, lei ou valor. É verdade que toda ação moral comporta uma relação ao real em que se efetua, e uma relação ao código a que se refere; mas ela implica também uma certa relação a si. Essa relação não é simplesmente "consciência de si", mas constituição de si enquanto "sujeito moral", na qual o indivíduo circunscreve a parte dele mesmo que constitua o objeto dessa prática moral, define sua posição em relação ao preceito que respeita, estabelece para si um certo modo de ser que valerá como realização moral dele mesmo. Para tal, age sobre si mesmo, procura conhecer-se, controla-se, põe-se à prova, aperfeiçoa-se, transforma-se. 
Também em 2014 publica-se uma matéria que apresenta as propostas dos presidenciáveis para a população LGBT, a reportagem destacou a situação ocorrida em debate televisionado em abrangência nacional, na qual um candidato comparou homossexuais a pedófilos e conclamou a sociedade a enfrentar esse segmento da população. Percebemos que os jogos de verdade envolvendo as dimensões pública e privada dos sujeitos se entrelaçam nas respostas dos candidatos, o cunho moral religioso se mistura com legislações e as instituições tradicionais familiares e religiosas que produzem discursos de verdade nas esferas políticas, jurídicas e sociais. Jogos de verdade (Foucault, 1999) são o conjunto de regras de produção de verdade, o conjunto de procedimentos que conduzem a um determinado resultado, que pode ser considerado - em função de seus princípios e de suas regras de procedimento - como válido ou não. Quem fala a verdade são indivíduos livres, os quais entram em consenso e estão inseridos em uma determinada rede de práticas e de instituições coercitivas.

\section{Armário de Vidro Blindado}

Em 2014 o veículo jornalístico circulou uma reportagem sobre o primeiro casamento entre pessoas do mesmo sexo realizado no cartório da cidade. Assinada por uma mulher cisgênera, o escrito ressaltou que esta era a primeira união oficial "homoafetiva" do município e lembrou que o Conselho Nacional de Justiça (CNJ) aprovou, em maio de 2013, a resolução que obriga os cartórios de todo o país a celebrar o casamento civil e converter a união estável homoafetiva em casamento (BRASIL, 2013).

A consagração do termo "Homoafetividade" veio a partir da publicação da obra "União homossexual: o preconceito e a justiça", da jurista Maria Berenice Dias (2000). A referida terminologia foi criada para justificar a inclusão das uniões entre pessoas do mesmo sexo no âmbito de proteção dos regimes jurídicos da união estável e do casamento civil, e com o intuito de se destacar que as uniões entre pessoas do mesmo sexo são pautadas no mesmo afeto romântico que justifica as uniões entre pessoas de sexo opostos. Isso foi feito por conta do preconceito social que afirmava que as uniões entre pessoas do mesmo sexo seriam motivadas por mera luxúria ou puro desejo erótico e não pelo sentimento de amor sublime que une duas pessoas de sexo oposto (COSTA; NARDI, 2015).

Homoafetivo é um termo comumente utilizado para definir casais cisgêneros homossexuais e, na grande maioria das vezes, é referenciado em situações que envolvam casamentos, direito a serviços e patrimônio e adoção de filhos. Lembramos que o termo heteroafetivo é utilizado em proporção muito menor e que o termo homoafetivo não é utilizado em nenhuma outra parte do mundo. Comumente o termo heterossexual é empregado para definir casais cisgêneros de sexo biológico diferentes.

Conforme Costa e Nardi (2015), o surgimento da homoafetividade aponta para a dificuldade na implementação de um direito democrático da sexualidade, uma vez que sexualidades não pautadas pelo amor romântico seguem política e moralmente deslegitimadas. A busca por igualdade de direitos não deve 
institucionalizar subjetividades, sob o risco de cair em um conservadorismo que reforça hierarquias sexuais.

Numa reportagem especial para o Dia dos Namorados, uma mulher cisgênera assina a entrevista com um casal de homens gays. Nesta, o termo homoafetivo aparece logo nas primeiras linhas, onde um casal cisgênero expõe os atravessamentos do relacionamento. $\mathrm{Na}$ reportagem encontramos um casal branco que namoram há três anos, dentro de uma mesma faixa etária e cursando ensino superior.

No que diz respeito às relações, a heternormatividade institui como referência um casal cisgênero heterossexual com compromisso civil, mesmo grupo etário e étnico-racial. O Armário de Vidro dos dois casais citados é blindado, pois o marcador social que o engloba é a inteligibilidade da cisheteronormatividade que higieniza as relações para a aceitação, ou seja, algumas pessoas são aceitas desde que capturados por determinadas normas.

Mesmo assim, ainda são casais que destoam da matriz heterossexual e por ambos serem do sexo masculino pode ser fator que desencadeie homofobia em suas diferentes esferas. É um tipo de vidro muito forte que também pode ser arranhado ou quebrado por regras sociais preconceituosas. $O$ que pretendemos refletir são quais exclusões se criam quando reconhecemos somente determinados sujeitos e relações e quais as normatividades produzidas por estes contextos quando os entrevistados e o veículo informativo produzem verdades, subjetividades e relações de poder sobre homens gays.

Armário de Vidro Temperado Estilhaçado

O armário de vidro temperado estilhaçado simboliza os discursos de poder e verdade sobre o corpo e subjetividade e a fragmentação violenta do sujeito. $O$ vidro temperado passa por tratamentos para modificar a sua dureza e resistência. Muitas vezes, as travestis submetem-se a procedimentos que modificam os seus corpos e projetam papeis e discursos de gênero. A população de travestis é tomada por resistência assim como os vidros temperados o são. Quando quebra, o vidro temperado se estilhaça em pequenos fragmentos.

No jornal investigado encontramos cinco reportagens que abarcavam essa população. Uma que trouxe a fala de uma celebridade após ser fotografada com uma travesti. Uma falando sobre a burocracia da busca pelo nome social no Estado do RS e três delas envolvendo o assassinato de travestis.

Duas foram assinadas por homens cisgêneros, duas por mulheres cisgêneras e uma não continha assinatura. Uma das reportagens tratou a travesti pelo gênero feminino durante todo o escrito trazendo o seu nome social. Uma alternou entre pronomes femininos e masculinos. Outra alternou entre pronomes masculinos e pronomes não binários, e duas nomearam pronomes masculinos ao referenciar as travestis, uma delas incluindo o nome social e a identificação do nome de registro civil no gênero masculino.

Dentre os apontamentos, destacam-se o baixo número encontrado de reportagens, o desrespeito pelo gênero reivindicado e que mais da metade dos enunciados abarcam uma violência explícita contra essa população. $O$ armário 
pouco protege a pessoa superexposta e colocada à margem das questões da sociedade. A patologização, fetichização e marginalização são forças violentas que estilhaçam os seus corpos e subjetividades de maneira simbólica e literal.

Sobre essas situações destacamos que na semana das Conferências Nacionais Conjuntas de Direitos Humanos, foi publicado o Decreto Presidencial № 8.727 de 28 de abril de 2016, que dispõe sobre o uso do nome social e o reconhecimento da identidade de gênero de pessoas travestis e transexuais no âmbito da administração pública federal (Brasil, 2016) e que de acordo com a pesquisa realizada pela Transgender Europe (TGEU), entre janeiro de 2008 e março de 2014, foram registradas 604 mortes de travestis e transexuais no Brasil.

Para Simpson (2015), travestis e transexuais são vistas pela medicina como seres portadores de patologia e tratadas por códigos de doenças que utilizam termos como "travestismo" e o "transexualismo". Os termos travestilidade e transexualidade foram criados pelo movimento social organizado para dizer que a questão dessa população é uma questão de identidade e de modo de viver.

As emergentes dessa população permeiam a batalha contra o estigma e a marginalização do seu grupo, a luta interdisciplinar a favor da despatologização do gênero, a criminalização da transfobia e programas de educação e promoção da qualidade de vida de pessoas travestis. A repercussão das violências contra essa população é tênue a produção de verdades instauradas pela mídia, quando não se respeitam as identidades ou ainda quando somente são vinculadas reportagens que negam a gama de complexidades do ser e viver travesti.

Armário de Vidro Transparente Acústico

A população de transexuais aparece uma vez em cada ano analisado. $\mathrm{Na}$ primeira informando que a Justiça autorizou uma pessoa transexual a mudar de nome "sem a operação de troca de sexo" (SIC). Em outra assinala que transexuais e travestis já podem solicitar o nome social e no último ano salienta que uma psicóloga transexual terá seu nome social incluído na carteira de identidade profissional.

A justiça tem concedido, em muitos casos de cirurgia, o direito de mudança de nome e redesignação do "sexo" em documentos de identidade, mas a decisão ainda depende do arbítrio dos juízes. O fato de a mudança documental depender, na maioria dos casos, da realização de cirurgia de transgenitalização tanto consagra a distância entre os diferentes saberes autorizados de médicos, psicólogos, operadores de direito, entre outros e as experiências concretas dos sujeitos sociais, quanto marca, sob a justificativa de "sanar" a inadequação entre sexo e gênero, a reinstaurarão de um perverso binarismo (CARRARA, 2010).

Os vidros acústicos impedem que os ruídos passem de um ambiente para 0 outro. Esse armário quase sempre é transparente, muito se vê, mas pouco ou nada se ouve. A constituição da sua proposta é eficaz, pois consegue inibir os sons que vem de dentro dele. A população de homens e mulheres transexuais tem a sua voz 
negada e não tem permissão para serem protagonistas da própria história, pois lhe são impostos discursos sobre o seu gênero e a sua sexualidade.

Os dados sociais da população de travestis e transexuais são estatisticamente infiéis, pois grande parte das vezes, os levantamentos feitos são referenciados junto da população de homens cisgêneros homossexuais. Referenciadas como homens gays com mais estereótipos femininos, tem mais uma vez desrespeitada a identidade de gênero reivindicada e a presente confusão desonesta entre gênero e sexualidade.

As políticas públicas emergentes para transexuais são diversas, desde o entendimento notório e didático sobre o que é transexualidade, passando por políticas de inclusão da diversidade de gênero e sexual. Esse processo poderia resultar na discussão e retirada do termo "transexualismo", disforia ou dimorfismo dos Códigos e Manuais de Doenças.

Nessa direção, Berenice Bento e Larissa Pelúcio (2012, p. 579) questionam: "Por que diagnosticar o gênero? Quem autoriza psicólogos, psiquiatras, endocrinologistas e outras especialidades que fazem parte das equipes multidisciplinares a avaliarem as pessoas transexuais e travestis como "doentes"?". As autoras ainda ponderam que, "se não existe nenhum exame clínico que conduza a produção do diagnóstico, como determinar a ocorrência do "transtorno"? Quais e como estabelecer os limites discerníveis entre "os transtornados de gênero" e "os normais de gênero"?" (BENTO; PELÚCIO, 2012, p. 579).

A identidade de gênero não é construída por processos cirúrgicos ou terapia hormonal, primeiramente porque essa decisão cabe a cada pessoa e lembrando que a identidade de gênero pode não ser consonante ao papel de gênero, ou seja, padrões de comportamento masculino ou feminino esperados para homens e mulheres em nossa sociedade (JESUS, 2012). Segundo, porque mesmo quando há o interesse nesses processos e procedimentos, eles são de difícil acesso, resultando na busca e utilização inadequada que podem afetar diretamente a relação saúde/doença da mulher e do homem transexual.

O atendimento interdisciplinar consiste no entendimento clínico, na hormônioterapia, no atendimento psicológico e psiquiátrico e na realização das cirurgias de transgenitalização e de caracteres sexuais secundários. Estes procedimentos foram normatizados pela Portaria GM n. 1.707, de 18 de agosto de 2008, do Ministério da Saúde (2008), que estabeleceu diretrizes técnicas e éticas para o processo transexualizador no SUS.

Os discursos produzem efeitos de verdade como à invisibilidade do homem transexual e a dogmatização de marcadores para o reconhecimento da identidade trans que marginalizam e excluem os sujeitos. Ressaltamos que o armário de vidro acústico tem seu vidro estilhaçado também, considerando o tanto de violências hediondas e direitos negados que a população de homens e mulheres transexuais sofre.

Armário de Vidro Fumê

Os vidros adesivados por películas em tons marrons ou cinza escuro recebem o nome de vidro fumê. Sua função abarca diferentes propósitos como 
segurança, a proteção de raios ultravioletas e a busca por privacidade. Os tons escuros escondem, em diferentes proporções, algo que está no compartimento interior e desperta a curiosidade fetichista daqueles que estão do lado de fora. Assim, muitas vezes se dão os discursos de verdade na vida de mulheres lésbicas cisgêneras. Foram encontradas duas reportagens que englobaram diretamente essa população e esse número traz algumas considerações pertinentes.

A escassez de material sobre mulheres lésbicas é um dos grandes adventos da heterossexualidade compulsória às mulheres para que exerçam, exclusivamente, papeis milenares instituídos. O desejo da mulher é extirpado em detrimento do lugar materno e a sua sexualidade permanece disponível à reprodução e ao desejo do homem. Rich (2010) propõe a ideia da heterossexualidade como uma instituição política que retira o poder das mulheres e que assegura o direito masculino de acesso físico, econômico e emocional sobre elas.

A invisibilidade lésbica está diretamente relacionada aos discursos de verdade dos lugares sexuais/reprodutivos e socioculturais das mulheres e da fomentação dos homens cisgêneros como figura matriz em diferentes âmbitos. $A$ heterossexualidade institucionalizada permeia os domínios da linguística com as denominações gramaticais que abarcam homens e mulheres (homens/humanos, pais, gays), do patriarcado (maternidade, função de cuidado emocional e doméstico, supremacia dos homens), da sexualidade (disposição e desejo absoluto pela figura do homem) e das desigualdades e violências.

No dia 29 de agosto é comemorado o Dia Nacional da Visibilidade Lésbica que também envolve a luta contra o machismo, contra a lesbofobia e em prol de uma revolução permanente que promova o espaço para as mulheres lésbicas nas discussões sobre diversidade social, sexual e de gênero. Uma das políticas públicas de saúde abarca a epidemiologia estatística e científica da mulher lésbica, buscando cobrir essa lacuna silenciosa a fim de alcançar as singularidades das mulheres trans e cis não heterossexuais.

\section{Armário de Vidro Cristal}

Totalizando dez enunciados envolvendo a população LGBT e marcas nacionais e internacionais, a análise de discurso dessa categoria fez pensar os efeitos de verdade de gênero e sexualidades imbricados ao cunho comercial e de inclusão a diversidade. $O$ vidro cristal pode ser considerado um tipo comum do material que é refinado e nobre, ou seja, muitas pessoas podem vê-lo e poucas pessoas podem adquiri-lo. Funciona como as estratégias de marketing que podem propagar-se numa ampla dimensão, mas que nem todos poderão efetivar a compra. Elas concretizam a sua função que é permear o grande público, contudo, como os cristais, são frágeis e a sua proposta mostra limites de alcance.

O merchandising age através de discursos que promovem efeitos de verdade sobre as pessoas. Tanto aquelas que fazem uso direto da marca e do produto, como aquelas que não o tem acesso. $O$ discurso capitalista produz identidades ao estipular quem adquire determinado produto e o lugar social que esse produto representa. Vincular a população LGBT a marcas conhecidas do grande público é 
uma faca de dois gumes, pois cola a visibilidade para as questões de gênero e sexualidade a recursos de (e discursos de) poder de venda e compra.

Há discursos de poder e resistência nas reportagens afirmando que pessoas LGBTs também podem ser associadas as suas marcas, ao tempo que regulam o lugar socioeconômico que os diferentes consumidores se encontram, ressaltando a supremacia de modelos de cor branca e cisgêneros e a invisibilidade negra e trans. As propagandas midiáticas instituem e transformam padrões de consumo e comportamento.

Como ressalta Foucault (2006), há efeitos de verdade que uma sociedade, como a ocidental, produz a cada instante. Produz-se verdade. Essas produções de verdades não podem ser dissociadas do poder e dos mecanismos de poder, ao mesmo tempo porque esses mecanismos de poder tornam possíveis, induzem essas produções de verdades, e porque essas produções de verdade têm, elas próprias, efeitos de poder que nos unem, nos atam.

Não tivemos o propósito de diminuir a importância da mídia e marketing LGBT. Inclusive, ressaltamos que a visibilidade sexual e de gênero se dá também por esse viés, contudo, achamos pertinente ressaltar que ao acoplar essas populações a alguma marca muitos perfis não são alcançados e que, ao pensarmos políticas de inclusão LGBT devemos ressaltar a diversidade encontrada entre esses sujeitos.

\section{DIREITOS SEXUAIS, DIREITOS HUMANOS E POLÍTICAS PÚBLICAS: ENCONTRANDO AS CHAVES PERDIDAS DOS ARMÁRIOS}

.Quatro reportagens abordaram o pior ataque a tiros da história dos Estados Unidos ocorrido em 12 de junho de 2016, o massacre na Boate LGBT Pulse em Orlando (Flórida) que matou 50 pessoas e deixou outras 53 feridas. Os escritos trouxeram notas de repúdio ao acontecimento e buscaram atualizar os leitores sobre a tragédia, elencando mensagens de anônimos e famosos que manifestaram a sua revolta e tristeza e tentaram confortar as vítimas e os seus familiares. Outros nove recortes fizeram apologia à inclusão, ao combate à desigualdade e ao preconceito e ao respeito às diferenças.

A esfera da sexualidade também tem sua política interna, desigualdades, e modos de opressão. Como em outros aspectos do comportamento humano, as formas institucionais concretas da sexualidade em um determinado tempo e lugar são produto da atividade humana. São imbuídas de conflitos de interesse e manobras políticas, ambas deliberadas e incidentais. Nesse sentido, o sexo é sempre político (RUBIN, 1981).

Dentre as reportagens analisadas, uma totalidade de 15 abordaram especificamente políticas públicas com planos e tratados de combate ao preconceito, ao bullying e a violência. A pesquisa aqui retratada iluminou pensamentos importantes sobre as discussões que perpassam as esferas pública e privada, social e subjetiva, pessoal e comunitária da população LGBT.

A Política Nacional de Saúde Integral da População LGBT foi instituída pela Portaria $n^{\circ} 2.836$ de $1^{\circ}$ - de dezembro de 2011 , sendo uma política que considera a 
orientação sexual e a identidade de gênero como determinantes sociais da saúde e visa à eliminação das iniquidades e desigualdades em saúde dessa população. Também foram criados, em 2011, os Comitês (nacional e estaduais) de Saúde Integral LGBT - espaços consultivos que apoiam a gestão do SUS e monitoramento da política - que têm sido fundamentais para a formulação, implantação e implementação das ações.

Nesse último ponto de problematização, insistimos na noção de que os discursos, ao instituírem padrões de normalidade produzem efeitos de verdade e conformam as mais diversas formas de viver os gêneros e as sexualidades. Nossa grande tarefa é resgatar a humanidade no existir e as políticas públicas e os direitos sexuais são ferramentas que auxiliam nessa jornada. Trazemos os armários reguladores de gênero e sexualidade sob a luz dos direitos humanos, pois problematizar os discursos de verdade é pensar no ser humano e em suas marcas sociais e políticas. Os armários também são as pessoas, pois as regulações são os discursos de poder e resistência que as constituem.

\section{CONSIDERAÇÕES FINAIS}

Pesquisas realizadas em pequenas cidades são importantes, pois regionalizam estudos quantitativos e qualitativos de temáticas selecionadas, deixando mais próximo da ciência e da população levantamentos que podem auxiliar no entendimento sócio histórico da demanda apresentada.

Pensando nessa problemática, a presente análise buscou reportagens que abarcassem LGBTs e encontrou apontamentos que fizeram a discussão tomar corpo. A separação por tipos de armários serviu como uma ferramenta metodológica que auxiliou no entendimento das políticas públicas necessárias para cada população.

A mídia escrita online e impressa produz discursos com efeitos de verdade, contudo, é pertinente ressaltar que a mídia está inserida num contexto mergulhado em forças que produzem discursos de verdade, ou seja, ela é produzida pela sociedade.

Dentre as primeiras considerações, ressaltamos a inexistência de reportagens envolvendo pessoas trans ou cis bissexuais. Essa população é esquecida e/ou estigmatizada em diferentes ambientes, dentro e fora dos movimentos sociais. A bissexualidade é considerada tabu ou invenção numa sociedade que instituem binarismos normativos e compulsórios.

A luta pelos direitos da população LGBT perpassa as diretrizes nacionais e internacionais dos Direitos Humanos, muito do que foi conquistado se deve ao remanejamento das suas configurações para a apropriação de políticas públicas com o Ministério da Saúde (acessibilidade e acolhimento de LGBTs no SUS e através do Sistema de Informação de Agravos e Notificação - SINAN), o Ministério da Segurança Pública (combate a violência) a Justiça Federal e Estadual (adoção, casamento, nome social), o Ministério da Cultura (políticas culturais voltadas para esse público), o Ministério da Educação (Parâmetros Curriculares Nacionais Orientação Sexual). 
Concluímos a pesquisa com muitas questões a serem retomadas e aprofundadas. Salientamos que há um caminho longo a ser percorrido na busca por uma sociedade mais igualitária e com menos estigma e exclusão para aqueles que fogem aos padrões cisheteronormativos e esperamos que esse escrito seja um estudo político e ético na luta pela construção e efetivação de uma sociedade mais equânime e justa.

\section{REFERÊNCIAS}

Bagagli, B. P. (2013). Máquinas discursivas, ciborgues e transfeminismo. Gênero, 14 (1), 11-27.

Bagagli, B. P. (2017). Orientação sexual na identidade de gênero a partir da heterossexualidade e cisgeneridade como normas. Letras Escreve, 7 (1), 137-164.

Bento, B; Pelúcio, L. (2012) Despatologização do gênero: a politização das identidades abjetas. Estudos feministas. 20 (2), 569-581. 
Butler, J. (2003). Problemas de gênero: feminismo e subversão da identidade. (R. Aguiar Trad.). Rio de janeiro: Civilização Brasileira. (Original publicado em 1990).

Carrara. S. (2010). Políticas e direitos sexuais no Brasil contemporâneo. In F. Pocahy (Org.) Políticas de enfrentamento ao heterossexismo: corpo e prazer (pp. 47-61). Porto Alegre: NUANCES.

Costa, A. B.; Nardi, H. C. (2015). O casamento "homoafetivo" e a política da sexualidade: implicações do afeto como justificativa das uniões de pessoas do mesmo sexo. Estudos Feministas, 23 (1), 137-150.

Decreto ํㅜ 8.727, de 28 de abril de 2016. (2016, 28 de abril). Dispõe sobre o uso do nome social e o reconhecimento da identidade de gênero de pessoas travestis e transexuais no âmbito da administração pública federal direta, autárquica e fundacional. Brasília, DF: Presidência da República, Subchefia Para Assuntos Jurídicos.

Dias, M. B. (2000). União Homossexual - Preconceito \& a Justiça. $1^{\mathrm{a} e}$ ed. Porto Alegre: Livraria do Advogado.

Foucault, M. (1999). Em defesa da sociedade. Curso no Collège de France, (M.E. Galvão Trad.). São Paulo: Martins Fontes. (Original publicado em 19751976).

Foucault, M. (2006). Estratégia, poder-saber 2.ed. (V.L.A. Ribeiro Trad.). Rio de Janeiro: Forense Universitária.

Foucault, M. (2007). História da sexualidade: o uso dos prazeres. (M. T. da Costa Albuquerque Trad.). Rio de Janeiro: Edições Graal. (original publicado em 1984).

Jesus, J. G. (2012). Orientações sobre identidade de gênero: conceitos e termos $2^{a}$ ed. Brasília: Guia técnico sobre pessoas transexuais, travestis e demais transgêneros, para formadores de opinião.

Portaria no 1.707 , de 18 de agosto de 2008. (2008, 18 de agosto). Dispõe sobre o processo transexualizador. Brasília, DF: Ministério da Saúde, Conselho Nacional de Saúde.

Carrara. S. (2010). Políticas e direitos sexuais no Brasil contemporâneo. In F. Pocahy (Org.) Políticas de enfrentamento ao heterossexismo: corpo e prazer. Porto Alegre: NUANCES. 
Pino, N. P. (2007). A teoria queer e os interex: experiências invisíveis de corpos des-feitos. Cadernos Pagu, (28), 149-174.

Resolução № 175, de 14 de maio de 2013. (2013, 14 de maio). Dispõe Habilitação, celebração de casamento civil ou conversão de união estável em casamento, entre pessoas do mesmo sexo. Brasília, DF: Ministério Público Federal, Conselho Nacional de Justiça.

Rich, A. (2010). Heterossexualidade compulsória e existência lésbica. Coalizão Nacional de Mulheres Trabalhadoras Sindicalizadas. (C.G. Vale Trad.). Revista BAGOAS, (05), pp. 17-44.

Rubin, G. (2003). Pensando sobre sexo: notas para uma teoria radical da política da sexualidade. (F. B. M. Fernandes Trad.). Cadernos Pagu, Campinas: Núcleo de Estudos de Gênero Pagu, (21), pp. 1-88.

Simpson, Keila (2012). Travestis: entre a atração e a aversão. In G. Venturini; V. Bokany (Orgs.). Diversidade sexual e homofobia no Brasil (pp. 109-117). São Paulo: Fundação Perseu Abramo

Sedgwick, E. K. (2007) A epistemologia do armário. (P. Dentzien Trad.) Cadernos Pagu. Dossiê sexualidades disparatadas. (28), pp. 19-54. 